\title{
CARBOHYDRATE-BINDING PROPERTIES OF AN IMMOBILIZED $\alpha$-D-GALACTOPYRANOSYL-BINDING PROTEIN (LECTIN) FROM THE SEEDS OF Bandeiraca simplicifolia
}

Thmothy T. Ross, Colleen E. Hayes, and Irwin J. Goldstein

Department of Biological Chemistry The University of Michigan, Ann Arbor, Michigan 48104

(U.S.A.)

(Received September 3rd, 1975; accepted for publication in revised form, November 14th, 1975)

\section{ABSTRACT}

The $\alpha$-D-galactopyranosyl-binding lectin from Bandeiraea simplicifolia has been coupled to cyanogen bromide-activated Sepharose 4B. Using this immobilized system, we have been able to study the interaction of the lectin with model carbohydrate-protein conjugates and polysaccharides, and to reaffirm this protein's carbohydrate-binding specificity.

The opportunity for the isolation of biopolymers containing $\alpha$ - $\mathrm{D}$-galactopyranosyl end-groups is demonstrated by the single-step purification of a new galactomannan from the seeds of Cassia alata.

INTKODUCTION

Carbohydrate-binding proteins from plant and invertebrate sources have gained prominence in recent years as analytical probes for the detection and preliminary characterization of complex carbohydrates, both in solution ${ }^{1}$ and on cell surfaces ${ }^{2}$. These proteins, also referred to as lectins and phytohemagglutinins, display a rather wide range of specificities toward the sugars which they bind ${ }^{3}$.

A few lectins have been chemically linked to insoluble matrices and employed for the isolation of polysaccharides ${ }^{4-6}$, glycoproteins ${ }^{7-11}$ and cells ${ }^{12,13}$.

We report here some properties of an insolubilized $\alpha$-D-galactopyranosylbinding lectin and its use in the isolation of polysaccharides containing terminal $\alpha$-D-galactopyranosyl end-groups.

EXPERIMENTAL

Materials and methods. - All simple sugars employed in this study were obtained from Pfanstiehl Laboratories, Inc., Waukegan, Illinois.

The $p$-azophenyl $\beta$-maltoside-bovine serum albumin (BSA) (14 residues of sugar/BSA molecule) and $p$-azophenyl $\beta$-lactoside-BSA (19 residues of sugar/BSA molecule) conjugates were available from a former study ${ }^{14}$; the $p$-azophenyl $\alpha-D-$ galactopyranoside-BSA conjugate (21 sugar residues/BSA molecule) and the $p$ - 
azophenyl 2-acetamido-2-deoxy- $\beta$-D-galactopyranoside-BSA conjugates (16 sugar residues/BSA molecule) were prepared by Lee Murphy and William Galbraith, respectively, in this laboratory. Hereafter, these conjugates will be referred to as galactoside-BSA, maltoside-BSA, lactoside-BSA, and 2-acetamido-2-deoxy-Dgalactoside-BSA.

Bandeiraea simplicifolia lectin was prepared by the procedure of Hayes and Goldstein $^{15}$. It was coupled to Sepharose 4B (Pharmacia Fine Chemicals, Inc., Piscataway, New Jersey) through the courtesy of Dr. Robert Bywater of Pharmacia Fine Chemicals, Uppsala, Sweden. Cyanogen bromide-activated Sepharose 4B (10 g, Pharmacia Fine Chemicals, Piscataway, N.J.) was processed according to the manufacturer's directions. Freeze-dried $B$. simplicifolia lectin $(100 \mathrm{mg})$ was dissolved in $0.1 \mathrm{M}$ sodium hydrogen carbonate plus $0.5 \mathrm{M}$ sodium chloride $(50 \mathrm{ml})$ and the drained, activated gel suspended in the lectin solution. The suspension was stirred gently overnight. Absorbance readings at $280 \mathrm{~nm}$ of the original and final solutions showed that virtually all $(98.5 \%)$ of the protein had been coupled to the gel. The lectin-gel was washed several times at pH 3 and 8 and finally suspended in $10 \mathrm{~mm}$ citrate buffer ( $\mathrm{pH} 3$ ) containing $0.05 \mathrm{M}$ sodium chloride and stored at $2^{\circ}$.

Coupling of B. simplicifolia lectin to Affi-Gel 10. - B. simplicifolia lectin [8 $\mathrm{mg}$ of lectin in $5.5 \mathrm{ml}$ of phosphate-buffered saline $(0.01 \mathrm{M}$ phosphate, $\mathrm{pH} 7.0,0.15 \mathrm{M}$ in sodium chloride and $0.1 \mathrm{~mm}$ in calcium chloride) containing $0.1 \mathrm{M}$ methyl $\alpha-\mathrm{D}-$ galactopyranoside as protecting sugar) was added to $1 \mathrm{~g}$ of Affi-Gel 10, an $N$-hydroxysuccinimide derivative of Bio-Gel (product of Bio-Rad Laboratories, Richmond, California). The slurry was kept for $10 \mathrm{~min}$ and then poured into a column $(0.9 \times 13 \mathrm{~cm})$, which was then washed thoroughly with phosphate-buffered saline.

Polysaccharides. - Larch arabinogalactan (Larix occidentalis) and galactoglucomannan of the eastern hemlock (Tsuga canadensis) were the gift of Prof. Bengt Lindberg, Stockholm University, Stockholm, Sweden. Dr. P. A. J. Gorin of Prarie Regional Laboratory, Saskatoon, Canada kindly supplied the galactomannan of the yeast Torulopsis gropengresseri ${ }^{16}$. Dextran B-1355-S was from a pervious $\operatorname{study}^{17}$ as was guaran ${ }^{15}$. The synthetic D-galactan ${ }^{18}$ was provided by Dr. P. T. Mora of the National Cancer Institute, National Institutes of Health, Bethesda, Maryland.

General assay procedures. - Carbohydrate was determined by the phenolsulfuric acid assay of Dubois et al. ${ }^{19}$. Carbohydrate determination of the galactomannan was based on a standard mixture composed of D-mannose and D-galactose in a molar ratio of $2: 1$, respectively.

Protein determination was assayed by absorbance at $280 \mathrm{~nm}$ and by a microbiuret determination ${ }^{20}$.

Hydrolysis of polysaccharide was conducted in sealed tubes at a concentration of $1 \mathrm{mg}$ of carbohydrate $/ 0.5 \mathrm{ml} 0.75 \mathrm{M}$ sulfuric acid for $6 \mathrm{~h}$ at $100^{\circ}$. Neutralization with calcium carbonate was followed by descending paper-chromatographic analysis of the hydrolyzate on Whatman No. 4 paper. The developing solvent was 1-butanolpyridine-water ( $6: 4: 3$ by volume); sugars were made visible by silver nitrate sprayreagent. 
Extraction and purification of the galactomannan. - Seeds of Cassia alata $(15 \mathrm{~g}$, obtained through the courtesy of Mr. T. Quintyne, Barbados, West Indies) were finely ground in a coffee mill and the meal (after removal of the seed integument) was extracted with water $(150 \mathrm{ml})$ for $3 \mathrm{~h}$ at $4^{\circ}$. The major portion of the viscous, supernatant solution was decanted and the remainder centrifuged in a Sorvall RC 2 centrifuge for $20 \mathrm{~min}$ at $4^{\circ}$ at $10,000 \times g$. To the combined, viscous, supernatant solution was slowly added 2 vols. of abs. ethanol while stirring magnetically. The resultant precipitate was washed successively with abs. ethanol, diethyl ether, and petroleum ether (b.p. $30-60^{\circ}$ ), and dried in a vacuum oven to give a light-tan powder $(1 \mathrm{~g})$. A stock solution $(1 \mathrm{ml})$ containing $1 \mathrm{mg} / \mathrm{ml}$ of the crude extract had $660 \mu \mathrm{g}$ of carbohydrate (phenol-sulfuric acid assay) and $350 \mu \mathrm{g}$ of protein (microbiuret assay). Hydrolysis and chromatographic analysis of the crude extract were conducted as described (Methods).

Affinity chromatography on a column of B. simplicifolia lectin-Sepharose 4B. A Pharmacia K9/30 column $(0.9 \times 30 \mathrm{~cm})$ was filled with $15 \mathrm{ml}$ of the B.simplicifolia lectin-Sepharose 4B gel previously equilibrated and washed exhaustively with phosphate-buffered saline. Samples of carbohydrate-protein conjugate $(5-10 \mathrm{mg})$, polysaccharide, or crude polysaccharide extract were layered onto the column. Fractions $(1.5$ or $2.0 \mathrm{ml}$ ) were collected on an automatic fraction-collector (flow rate $3 \mathrm{ml} / \mathrm{h}$ ) and monitored for carbohydrate (phenol-sulfuric acid assay, absorbance at $490 \mathrm{~nm}$ ), protein (absorbance at $280 \mathrm{~nm}$ ) or carbohydrate-protein conjugate ${ }^{14}$ (absorbance at $370 \mathrm{~nm}$, characteristic of the phenylazo linkage).

After ihe effluent had reached a base level (absorbance $\leq 0.01$ ), a solution of $0.5 \mathrm{M} D$-galactose in the equilibrating buffer was added to the column to elute any specifically bound carbohydrate. The eluted fractions were exhaustively dialyzed against phosphate-buffered saline and monitored as already described.

Gas-liquid chromatography of the alditol acetates of galactose and mannose ${ }^{21}$ were conducted with an F \& M Scientific model 402 gas chromatograph by using a 2-m, 3\% ECNSS-M column (Applied Science Laboratories, State College, Pennsylvania).

\section{RESULTS}

The elution patterns of the four model carbohydrate-protein conjugates studied in this investigation are presented in Fig. 1. It can be observed that the maltoside-BSA conjugate was eluted with the void volume being neither bound nor retarded. The lactoside-BSA conjugate was retarded but did not bind to the column; it eluted as a major and minor component, perhaps because of two populations of conjugate. The sccond pcak co'id also be attributed to overloading of the column. The 2-acetamido-2-deoxy-D-galactoside-BSA conjugate was both retarded and bound, approximately $22 \%$ ( $1.6 \mathrm{mg}$ of the $7.3 \mathrm{mg}$ added to column) being specifically bound. The galactoside-BSA conjugate was retarded and very strongly bound by the lectin column, $4.1 \mathrm{mg}$ of the $4.8 \mathrm{mg}(85 \%)$ applied to the column being subsequently eluted in the presence of $0.5 \mathrm{M} \mathrm{D}$-galactose. 


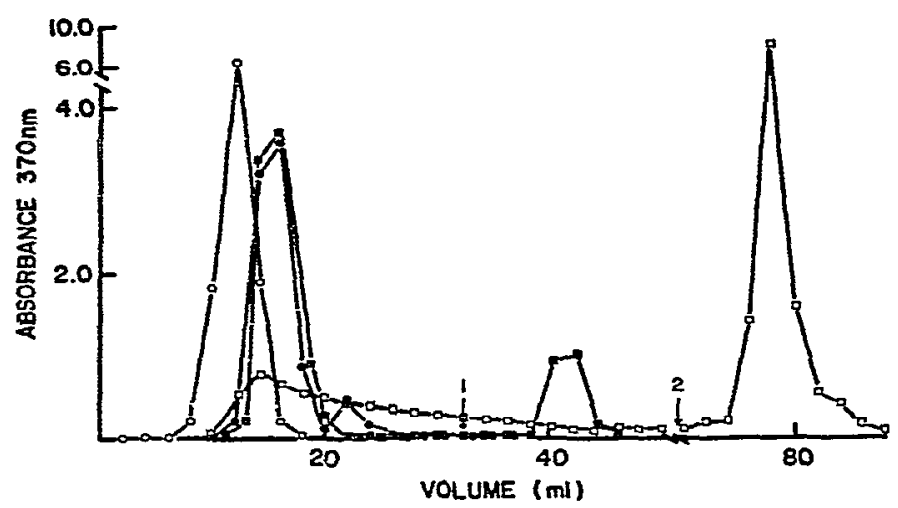

Fig. 1. Elution profile of model carbohydrate-protein conjugates on a column of $B$. simplicifolia lectin-Sepharose 4B. Conjugates were added and eluted separately. Arrow 1 indicates the point at which $0.5 \mathrm{M}$ D-galactose was added to the column to elute 2-acetamido-2-deoxy-D-galactoside-BSA conjugate. Arrow 2 indicates the point at which D-galactoside-BSA conjugate was eluted with $0.5 \mathrm{M}$ D-gaiactose-containing buffer. -O-, maitoside-BSA; - - , lactoside-BSA; - $\square-$, Dgalactoside-BSA; - E-, 2-acetamido-2-deoxy-D-galactoside-BSA.

Several polysaccharides were examined for their capacity to bind to the lectin column, and the results are presented in Fig. 2. Dextran B-1355-S (10 mg) was eluted in the void volume, no significant binding being observed $(<2 \%)$ upon elution with $0.5 \mathrm{M} \mathrm{D}$-galactose. Larch arabinogalactan was definitely retarded, but only a small proportion (5\%) was bound and displaced by D-galactose. The same was true of the chemically synthesized D-galactan.

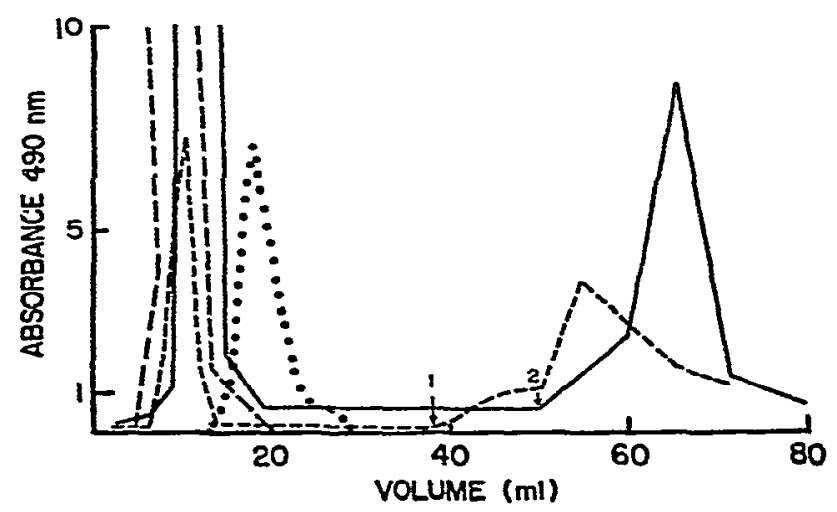

Fig. 2. Elution profile of polysaccharides on the column of B. simplicifolia lectin-Sepharose 4B. Polysaccharides were added and eluted separately from the column. Arrow 1 indicates the point at which D-galactose was added to the column to elute the galactoglucomannan of eastern hemlock. Arrow 2 indicates the point at which D-galactose was added to elute the yeast galactomannan. - - Dextran B-1355-S; —_ yeast (Torulopsis gropengiesseri) galactomannan; ...- eastern hemlock (Tsuga canadensis) galactoglucomannan; .... larch (Larix occidentalis) arabinogalactan. 
On the other hand, approximately $40 \%$ of the galactoglucomannan from eastern hemlock was selectively bound and eluted by $0.5 \mathrm{M} \mathrm{D}$-galactose solution. The same pattern was observed for the yeast galactomannan (Torulopsis gropengiesseri), approximately $38 \%$ of the polysaccharide being selectively bound by the lectin column.

In a study of the binding of the galactoside-BSA conjugate to a column of B. simplicifolia lectin-Affi-Gel $10,50 \%$ of the $2.2 \mathrm{mg}$ of conjugate added to the column was bound.

In several trials, it was shown that guaran, the galactomannan from Cyamopsis tetragonolobus, would bind to the lectin-Sepharose 4B column to the extent of 75-85\% when $5 \mathrm{mg}$ of the polysaccharide was applied. Conversely, the lectin-Affi-Gel 10 column was not as efficient in binding guaran, and no further studies were conducted with this column.

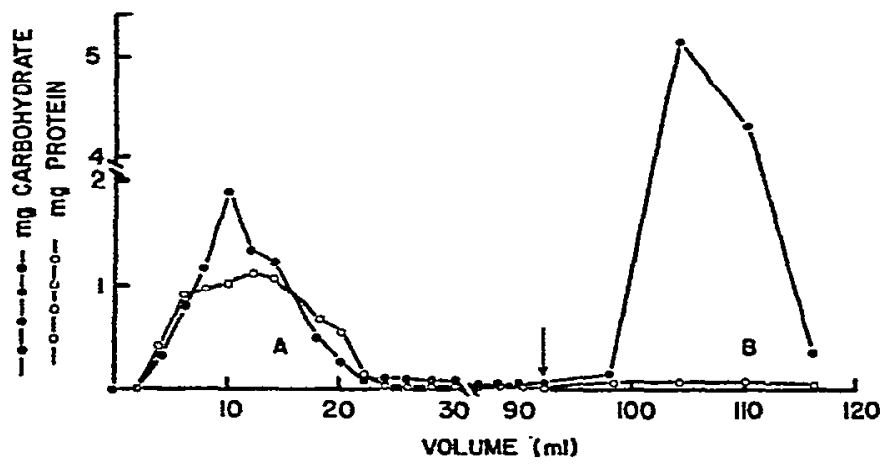

Fig. 3. Elution profile of the extract from Cassia alata seeds on a column of $B$. simplicifolia lectinSepharose 4B. The arrow indicates the point at which elution with $0.5 \mathrm{M} \mathrm{D}$-galactose was commenced. -O-, mg protein; - m carbohydrate.

Fig. 3. presents the elution profile of a crude extract from the seeds of Cassia alata on the lectin-Sepharose 4B column. Because of the highly viscous nature of the crude extract, a dilute solution ( $25 \mathrm{mg}$ of carbohydrate in $12 \mathrm{ml}$ of buffer) was applied to the column. It may be noted (Fig. 3) that the polysaccharide cluted by $0.5 \mathrm{M}$ D-galactose contained virtually no protein. Pure galactomannan $(9.0 \mathrm{mg})$ was eluted, which upon hydrolysis gave galactose and mannose as the sole sugars observed, whereas the crude extract also contained xylose and glucose, as determined by paperchromatographic analysis. Quantitation of the two sugars as their alditol acetates by g.l.c. gave a molar ratio of galactose: mannose of 1:4.3.

DISCUSSION

The results reported herein demonstrate that the $\alpha$-D-galactopyranosyl-binding protein (lectin) from $B$. simplicifolia seeds retains both its activity and carbohydrate- 
binding specificity when covalently linked to cyanogen bromide-activated Sepharose 4B. Using synthetic model carbohydrate-protein conjugates, we have been able to confirm the carbohydrate-binding specificity of the lectin ${ }^{15}$. Of the various conjugates examined for their capacity to bind to the affinity column, only the $\alpha-D-$ galactoside-BSA conjugate was strongly bound, although the 2-acetamido-2-deoxyD-galactoside-BSA conjugate also displayed binding capacity.

-Of a series of polysaccharides investigated for their capacity to interact with the immobilized lectin, dextran B-1355-S (an $\alpha$-D-glucan) was eluted with the void volume, and larch arabinogalactan (containing $\beta$-D-galactopyranosyl end-groups) was retarded but not bound. On the other hand, a galactoglucomannan from eastern hemlock (molar ratio galactose:glucose:mannose, 1:1:3) and a yeast galactomannan from Torulopsis gropengiesseri were both bound to the column to a moderate extent. Both of these polysaccharides contain non-reducing, terminal $\alpha-D$-galactopyranosyl groups.

The most dramatic utilization of the immobilized $B$. simplicifolia lectin column was undoubtedly exemplified by the demonstration that a new galactomanan could be purified in a single operation from a crude extract, free of protein and other "contaminating" polysaccharides, such as xylan and glucan.

Purification of galactomannans is generally achieved by precipitation of their barium or copper complexes, followed by regeneration in the presence of acid and subsequent precipitation by ethanol ${ }^{22}$. After purification has been repeated several times, "contaminating" protein may be removed by the Sevag procedure ${ }^{23}$. In the present procedure, 5-10 mg quantities of galactomannan can be isolated in a single step by affinity chromatography, thus affording sufficient material for chemical characterization.

Methods such as the one described here should be especially useful for the isolation of specific carbohydrate-containing macromolecules.

\section{REFERENCES}

1 I. J. Goldsten, Methods Carbohydr. Chem., 6 (1972) 106-119.

2 G. L. Nicolson, Int. Rev. Cytol., 39 (1974) 89-190.

3 H. Lis AND N. Sharon, Amm. Rev. Biochem., 42 (1973) 541-574.

4 K. O. Lloyd, Arch. Biochem. Biophys., 137 (1970) 460-468.

5 E. H. DonNeliy AND I. J. GoldstenN, Biochem. J., 118 (1970) 679-680.

6 R. J. Doyle, D. C. Birdsell, and F. E. Young, Prep. Biochem., 3 (1973) 13-18.

7 K. Asperg and J. Porath, Acta Chem. Scand., 24 (1970) 1839-1841.

8 M. L. Dufau, T. Tsuruhura, And K. J. CATT, Biochinl. Biophys. Acta, 278 (1972) $281-292$.

9 I. E. Liener, O. R. Garrison, ANd Z. PkAVde, Biochem. Biophys. Res. Commun., 51 (1973) 436443.

10 J. P. Susz, H. I. Hof, And E.:G. Brunwgrailer, FEBS Letters, 32 (1973) 289-292.

11 M. I. Hayman And M. J. CRimpton, Biochem. Biophys. Res. Comnun., 47 (1972) $923-930$.

12 G. M. Edelman, U. Rumshnuser, and C. ₹. Millette, Proc. Nat. Acad. Sci. U.S., 68 (1971) $215:-2157$.

13 I. BETEL ANd K. J. VANDEN BERG, Eur. J. Biochem., 30 (1972) 571-578.

14 P. N. IYER AYD I. J. GoldSTEIN, Immunochemistry, 10 (1973) 313-322.

15 C. E. HAYES AND I. J. GolDSTEIN, J. Biol. Chem., 249 (1974) 1904-1914.

16 P. A. J. Gorn, J. F. T. SpeNCER, AND D. E. EveleIGH, Carbohydr. Res., 11 (1969) $387-398$. 
17 L. L. So AND I. J. Goldstein, J. Biol. Chem., 242 (1967) 1617-1622.

18 P. T. Mora, J. W. Wood, AND V. W. MCFarland, J. Am. Chem. Soc., 82 (1960) 3418-3421.

19 M. Dubois, K. A. Gllye, J. K. Hamlton, P. A. Rebers, and F. Smith, Anal. Chem., 28 (1956) 350-356.

20 J. JaNATOVA, J. K. FulLER, AND M. J. HuNTER, J. Biol. Chem., 243 (1968) 3612-3622.

21 R. G. SPIRo, Methods Enzymol., 28 (1972) 3-43.

22 I. C. M. Dea and A. Morrison, Adv. Carbohydr. Chem. Biocńem., 31 (1975) 241-312.

23 A. M. Staub, Methods Carbohydr. Chem., 5 (1965) 5-6. 